\title{
Insight into the Pore Structures and Its Impacts on Movable Fluid in Tight Sandstones
}

\author{
Dazhong Ren $\mathbb{D}^{1},{ }^{1,2,3}$ Fu Yang, ${ }^{2}$ Rongxi Li, ${ }^{3}$ Desheng Zhou, ${ }^{1}$ Dengke Liu $\mathbb{D},{ }^{2,4}$ and Ying Li $^{3}$ \\ ${ }^{1}$ Shaanxi Key Laboratory of Advanced Stimulation Technology for Oil \& Gas Reservoirs, Xi'an Shiyou University, \\ Xi'an 710065, China \\ ${ }^{2}$ Key Laboratory of Coal Resources Exploration and Comprehensive Utilization, Ministry of Land and Resources, \\ Xi'an 710021, China \\ ${ }^{3}$ School of Earth Science and Resources, Chang'an University, Xi'an 710054, China \\ ${ }^{4}$ School of Human Settlements and Civil Engineering, Xi'an Jiaotong University, Xi'an 710054, China \\ Correspondence should be addressed to Dazhong Ren; petro_gas@163.com
}

Received 3 July 2020; Revised 7 September 2020; Accepted 9 December 2020; Published 21 December 2020

Academic Editor: Hualei Zhang

Copyright ( 2020 Dazhong Ren et al. This is an open access article distributed under the Creative Commons Attribution License, which permits unrestricted use, distribution, and reproduction in any medium, provided the original work is properly cited.

\begin{abstract}
Both the characteristics of pore structure and movable fluid are significant properties in controlling the flow regularity in pores in tight sandstones. However, the governing factors that affect the fluid flow features will still be a myth. In our research, the western area of the Sulige gas field was chosen as the research region, and various kinds of experiments were conducted. Three reservoir groups, including intergranular-dissolved pore type, dissolved-intercrystalline pore type, and pore plus microcracks type were identified on the basis of pore development features. The results suggest that the intergranular-dissolved pore type has a more prominent influence on the high movable fluid saturation and larger pores. Both large throat sizes and homogeneous porethroat degree demonstrate high movable fluid saturation. The increment of the thickness of water-film resulted from hydrophilic enhancement, indicating that an increased hydrophilic will decrease the movable fluid saturation and block the throats. The reservoirs of different pore combination types are closely related to the gas content of the reservoir.
\end{abstract}

\section{Introduction}

As the representative of the unconventional gas reservoir, tight sandstone reservoir is being paid attention to by researchers with the progress of exploration and exploitation and the depletion of conventional reservoir [1-5]. Understanding the pore structures of tight sandstones was the basis of investigating storage, transport properties, and development capability of oil and gas reservoirs [6-9]. The tight sandstone reservoir has the characteristics of poor physical property (porosity range between $8 \%$ and $10 \%$, permeability generally less than $1 \times 10^{-3} \mu \mathrm{m}^{2}$ ), small radius of pore and throat (the proportion of pores which radius fewer than $1 \mu \mathrm{m}$ generally over $50 \%$ ), complex pore structures, and serious heterogeneity [10-14]. In addition to physical property analysis, rock core observation and so forth, casting sections
(TS), scanning electron microscope (SEM), drainage and imbibition tests, small-angle and ultrasmall-angle neutron scattering (SANS and USANS), and other techniques were applied for pore-throat structure analysis purposes in tight sandstone reservoirs for several decades [15-19]. Therefore, the pore structures and its governing factors of tight sandstones need further study.

The movable fluid percentage is one of the significant parameters for recoverable reserves, and pore-throat characteristics have an important impact on it [20-22]. The nuclear magnetic resonance (NMR) technique has been extensively used for studying movable fluid saturation in porous media [23]. The irreducible water saturation in a tight sandstone reservoir is commonly higher than that in a conventional one, which generally in micropores corresponding to $T_{2}$ cutoff less than $10 \mathrm{~ms}$ and the combination of small throats and 
large pores. Hence, it is of great significance to evaluate the pore network and fluid flowability for the purpose of hydrocarbon development strategies.

In this research, the core samples from the Lower Shihezi group and Shanxi group of Sulige gas field are tested using casting sections and SEM to observe the characteristics of the pore-throat structure, clay minerals content and porethroat structures parameters are determined on the basis of $\mathrm{X}$-ray diffraction (XRD) and mercury injection data, a comprehensive study is carried out with NMR technique to study the characteristics of movable fluid saturation, and an experiment is conducted with gas-water relatively permeability technique to elucidate the wettability. The effect of porethroat characteristics on the movable fluid percentage is discussed in the end.

\section{Materials and Methods}

2.1. Geological Setting. Sulige gas field is located in the northwestern part of Ordos basin in China, and the tectonic is simple, which is a west-dipping monoclinal structure with an inclination of 1 degree (Figure 1(a)). The main producing formations in the Ordos basin include the Lower Shihezi group and Shanxi group of the Permian system [24-27]. Their porosity ranges from $4.11 \%$ to $15.19 \%$, with an average of $8.76 \%$; their permeability ranges from 0.17 to $6.88 \mathrm{mD}$, with an average of $0.46 \mathrm{mD}$, which indicates that the reservoir is a typical tight sandstone gas reservoir [28].

2.2. Samples. Eight tight sandstone true cores with a length of $5.50 \mathrm{~cm}$ and a diameter of $2.54 \mathrm{~cm}$ were collected from $8^{\text {th }}$ Member of Permian Lower Shihezi (He 8) and the $1^{\text {st }}$ Member of Permian Shanxi (Shan 1) tight sandstone reservoirs of the Sulige gas field of the Ordos basin in China (Figure 1(b)). The simulated formation water with a $\mathrm{CaCL}_{2}$ salinity of $25000 \mathrm{mg} / \mathrm{L}$ is prepared. Before the tests, all the samples were oil washed, dried, and vacuum for the purpose of the experiment procedure. The porosity and permeability were tested followed by casting sections, SEM, CL, constant-rate mercury injection, clay mineral X-ray diffraction, high-pressure mercury injection, gas-water relative permeability, and NMR experiments.

\subsection{Experimental Methods}

2.3.1. Casting Section (CS). ZT-1F Casting Instrument was used to make the casting sections in vacuum conditions. The samples were polished by sandpapers, then using T1502 glue to shape it, and the thickness of the samples should be $0.03 \mathrm{~mm}$. The Leica Dmrxhc polarizing microscope was used to examine the particle characteristics, pore structure types, and clay mineral features.

2.3.2. Scanning Electron Microscope (SEM). FEI Quanta 400 FEG SEM was used to study pore structure characteristics and mineral features of samples. The fragments were polished by sandpapers, and the thickness of the samples is less than $0.15 \mathrm{~cm}$. The samples were gold-coated and placed for secondary electron imaging (SE). The resolution of SEM was $3.5 \mathrm{~nm}$.
2.3.3. Cathode Luminescence (CL). CL8200MK5 Cathodoluminescence was used to examine clay mineral features of samples after the casting sections were produced. The beam current was $15 \mathrm{kV}$, and the beam voltage was $300 \mu \mathrm{A}$ for all samples because of the relative high calcite content.

2.3.4. High-Pressure Mercury Injection (HPMI). The pore structure quantitative characteristics were performed on a Micromeritics AutoPore IV 9520 mercury porosimeter following the standard SY/T 5346-2005 of China [29]. The maximum intrusion pressure was $200 \mathrm{MPa}$. This corresponds to a pore radius of $3.6 \times 10^{-3} \mu \mathrm{m}$. The mercury was intruded into the samples with the pressure increased. There were only intrusion curves obtained.

2.3.5. Constant-Rate Mercury Injection (CRMI). The subtle differences of pore and throat were performed on ASPE730 Coretest Systems following the standard SY/T 5346-2005 of China [29]. Maximum intrusion pressure was 6.2 MPa, corresponding to a pore-throat size of $0.12 \mu \mathrm{m}$ under the conditions of a quasistatic constant injection rate of $5 \times 10^{-5} \mathrm{~mL} \min ^{-1}$.

2.3.6. Clay Mineral X-Ray Diffraction (XRD). RIX2100 fluorescence spectrophotometer was used to analyse the quantitative features of clay minerals. The content of the element has a positive relationship with diffraction intensities, and the clay minerals types and content can be calculated by element combination.

2.3.7. Wettability Tests. The Dataphysics contact angle apparatus was used to determine the wettability. The pendant drop method was applied, and the contact angles were calculated three times. All samples were polished first, and the initial and stable contact angles were measured. Averaged contact angles were used to determine the wettability.

2.3.8. Nuclear Magnetic Resonance Technique (NMR). The MINI-MR NMR apparatus was used to measure the movable fluid percentage. The samples were first saturated for more than $24 \mathrm{~h}$ with simulated formation water after being vacuumed for $24 \mathrm{~h}$ following the standard SY/T 5336-2006 in China [30]. Then put the samples into the NMR apparatus to examine the $T_{2}$ spectrum.

\section{Results and Discussion}

3.1. Reservoir Classification. The NMR test and other experiments results show that the tight sandstone reservoirs of the Sulige gas field can be divided into three types based on pore types: reservoirs with the intergranular-dissolved pore type (RIDP), reservoirs with the dissolved-intercrystalline pore type (RDIP), and reservoirs with pore plus microcracks (RPPM). The pore type is an important parameter of the microcosmic characteristics of the reservoir, which is a comprehensive characterization of the microscopic pore structure. Therefore, the classification of reservoirs based on the pore type combination is an important reference for the rational development of reservoirs, which takes full advantage of microparameters and macroscopic properties. The reservoir type classification is based on the shape of $T_{2}$ 


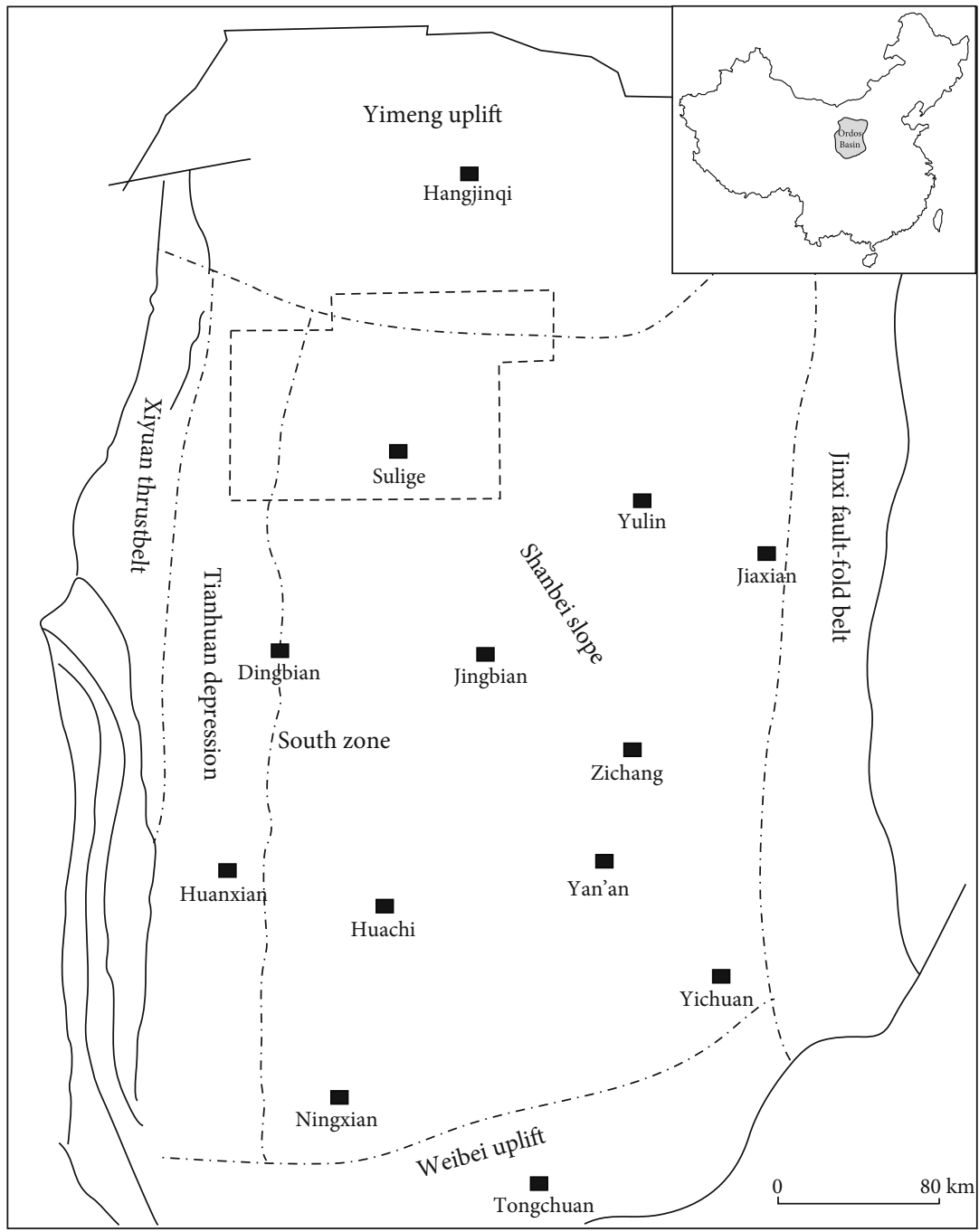

다 Sample location

- Boundary of first class tectonic unit

$\Longleftarrow$ Boundary of the basin

(a)

Figure 1: Continued. 


\begin{tabular}{|c|c|c|c|c|}
\hline System & Series & Formation & Thickness & $\begin{array}{c}\text { Lithology } \\
\text { profile }\end{array}$ \\
\hline Triassic & Lower & Liujiagou & $202-422$ & 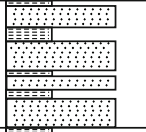 \\
\hline \multirow{4}{*}{ Permian } & \multirow{2}{*}{ Upper } & Shiqianfeng & $200-345$ & 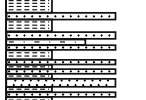 \\
\hline & & $\begin{array}{l}\text { Upper } \\
\text { Shihezi }\end{array}$ & $130-160$ & आח \\
\hline & \multirow{2}{*}{ Lower } & $\begin{array}{l}\text { Lower } \\
\text { Shihezi }\end{array}$ & $140-160$ & 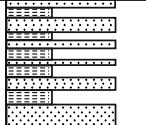 \\
\hline & & Shanxi & $90-120$ & 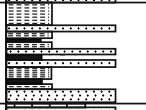 \\
\hline \multirow{2}{*}{ Carboniferous } & Upper & Taiyuan & $60-80$ & 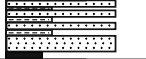 \\
\hline & Middle & Benxi & $10-40$ & 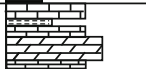 \\
\hline \multirow{5}{*}{ Ordovician } & Upper & Beiguoshan & $0-330$ & 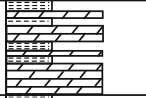 \\
\hline & Middle & Pingliang & $130-480$ & 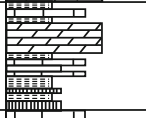 \\
\hline & \multirow[t]{3}{*}{ Lower } & Majiagou & $400-600$ & 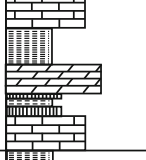 \\
\hline & & Liangjiashan & $100-200$ & 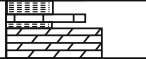 \\
\hline & & Yeli & $60-170$ & 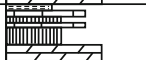 \\
\hline 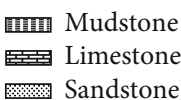 & & $\begin{array}{l}\mathrm{D} \\
\mathrm{C}\end{array}$ & $\begin{array}{l}\text { olomite } \\
\text { oal bed } \\
\text { ypsum }\end{array}$ & \\
\hline
\end{tabular}

(b)

Figure 1: (a) Location map of the research area with inset map of the Ordos basin region (upper right) and (b) stratigraphic column from Ordovician Majiagou formation to Triassic Liujiagou formation in the northern Ordos basin [24, 28].

distribution, the estimation of particle size and sorting, the amount and type of cements, and pore and throat structure characteristics.

3.1.1. Images. The main pore types of RIDP are intergranular and dissolved pores, which have undergone mechanical compaction and dissolution $[10,11]$. The radius of the intergranular pores is generally between $30 \mu \mathrm{m}$ to $80 \mu \mathrm{m}$, and the radius of the dissolved pores which is caused by acid fluid dissolution is generally between $10 \mu \mathrm{m}$ to $40 \mu \mathrm{m}$ (Figures 2(a) and 2(b). According to the CL pictures, the type of reservoir interstitial is mainly kaolinite (Figure 2(c). The overall porosity of the residual pelletized reservoir is high, and the pore size and connectivity are good.

The dissolution of the study area is common, the feldspar and lithic fragment dissolution are the main, which indicates that the study area is the mainly acidic hydrocarbon for RDIP (Figure 2(d)). The effect of dissolution on the reservoir properties is improved to a certain extent, and the porosity is increased. But the secondary dissolution has increased the nonhomogeneity of the reservoir to a certain extent and provided the material basis for the later clay mineral cementation to form intergranular micropores that have no reservoir and seepage capacity (Figures 2(e) and 2(f)).

The microcracks of the study area are almost diagenetic microcracks (RPPM), which are usually caused by strong mechanical compaction, so the quality and the porosity of the rock samples which have developed microcracks are pretty low (Figures 2(g) and 2(h)). Porosity caused by compaction becomes smaller, meanwhile, the development of compaction enhances the pressure- 


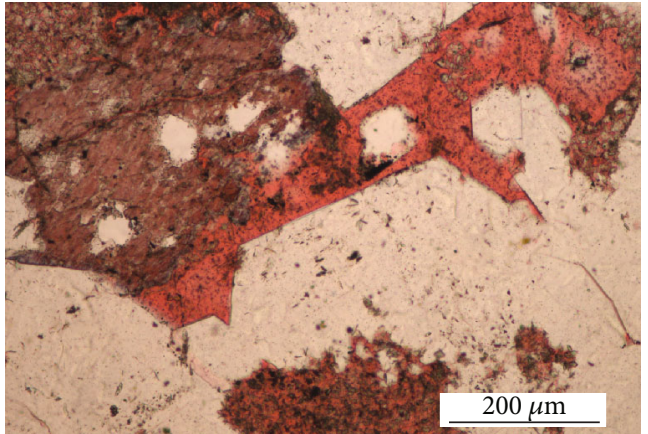

(a)

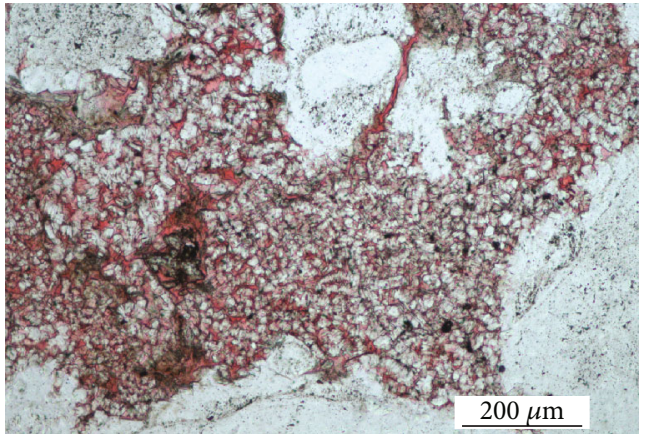

(d)

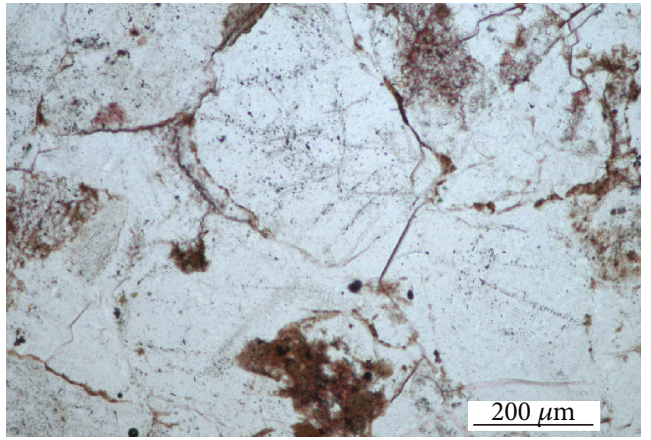

(g)

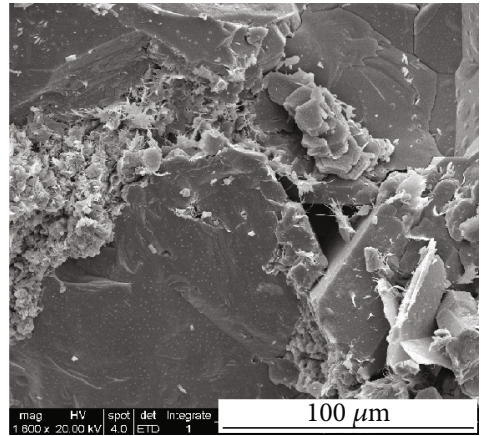

(b)

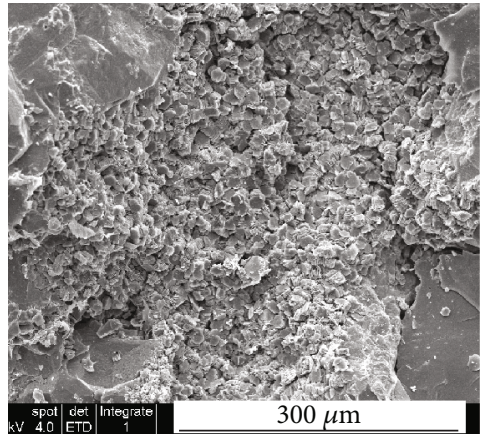

(e)

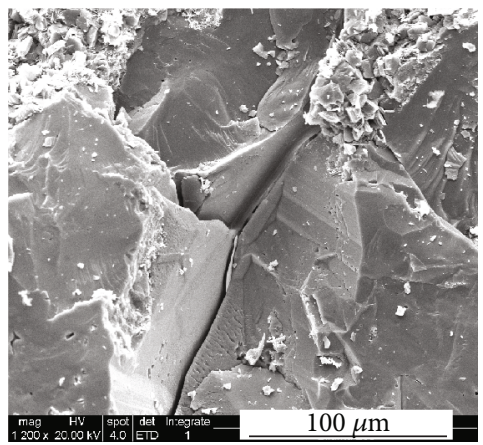

(h)

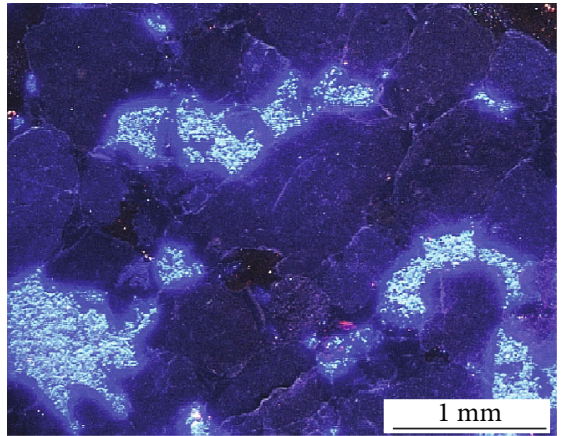

(c)

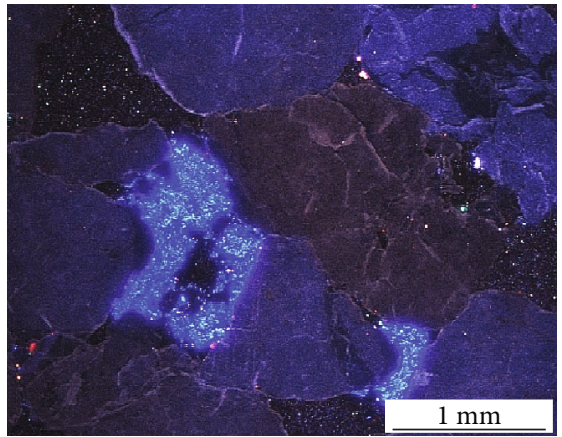

(f)

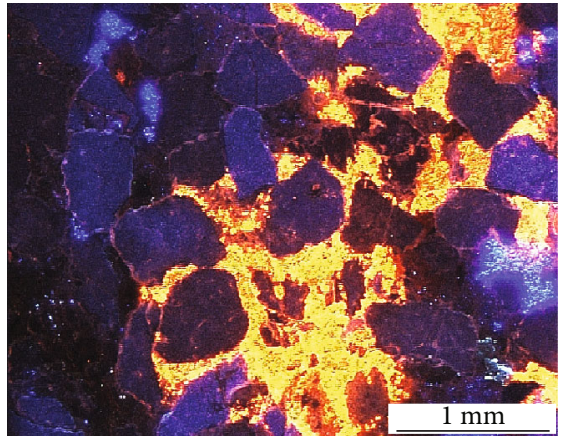

(i)

Figure 2: Casting section (a, d, g), SEM (b, e, h), and CL (c, f, i) images of the three typical samples.

dissolving effect. Therefore, pores such as kaolinite, carbonate, and the like are filled with pores, resulting in further reduction of pore space (Figure 2(i)).

3.1.2. HPMI. The average porosity of the samples with the RIDP is $13.82 \%$, and the average permeability is $0.58 \mathrm{mD}$ (Table S1). The capillary pressure curve shows that the threshold pressure and the median pressure of the reservoir are both low. Some sample of the capillary pressure curve is divided into obvious two-stage type. Low discharge pressure is regarded as a sign of microcrack development. The platform segment of the curve is clear, and the final mercury saturation is high, the main proportion of the radius ranges from 0.80 to $4.16 \mu \mathrm{m}$ (peak around $2.64 \mu \mathrm{m}$ ), while the most contribution value of the pore-throat radius to permeability is $4.15 \mu \mathrm{m}$, the great difference in peak means the seepage capacity of this reservoir type is mainly contributed by relatively large pores (Figure 3(a)).
The average porosity of RDIP in the study area is $8.12 \%$, and the average permeability is $0.13 \mathrm{mD}$ (Table S1). The capillary pressure curve shows that there is an increase both in the threshold pressure and median pressure of the reservoir with the dissolved pores compared with the reservoir with intergranular pores. However, the capillary pressure of this type of reservoir changed significantly. Meanwhile, it has a shorter and less obvious platform segment, and the main proportion of the radius ranges from 0.10 to $0.63 \mu \mathrm{m}$ (peak around $0.40 \mu \mathrm{m}$ ), while the most contribution value of the pore-throat radius to permeability is $0.63 \mu \mathrm{m}$ (Figure $3(\mathrm{~b})$ ).

The average porosity of RPPM in the study area is $7.44 \%$, and the average permeability is $1.42 \mathrm{mD}$ (Table S1). The median radius is lower than that of the first two types of samples, indicating that this type of reservoir has the least pore throat development and the maximum mercury saturation. Pore throat mercury saturation at $0.008 \sim 7.100 \mu \mathrm{m}$ 


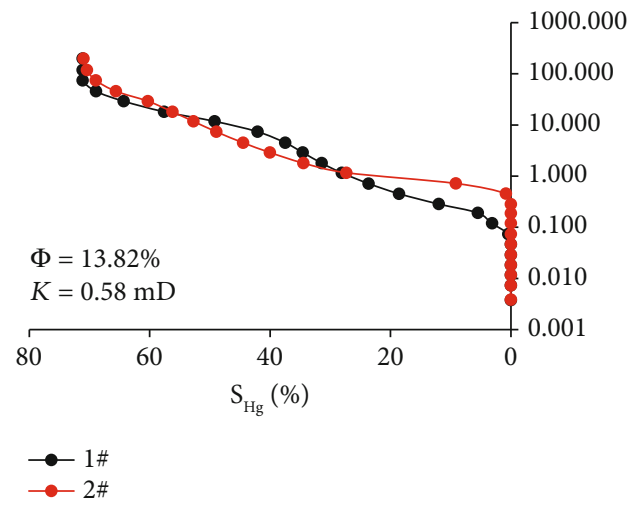

(a)

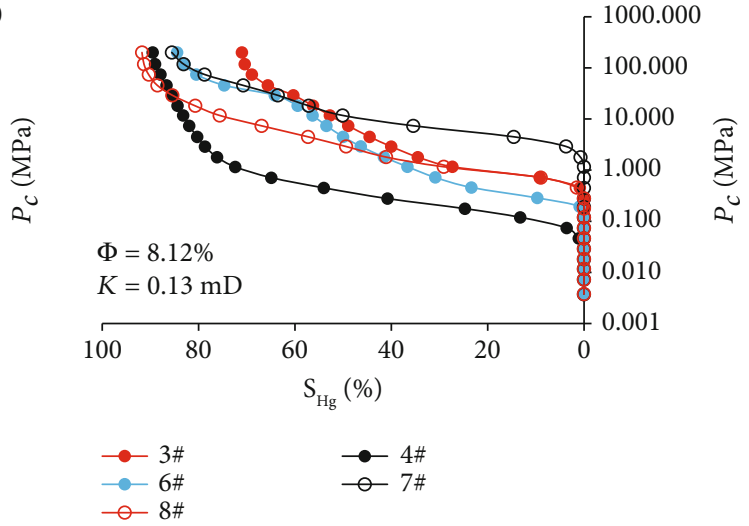

(b)

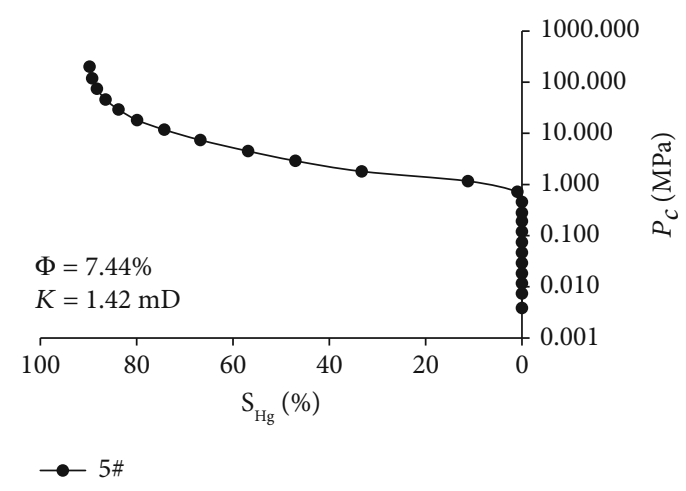

(c)

FIGURE 3: High-pressure mercury injection curves of the three types of reservoirs.

has developed, indicating strong pore throat heterogeneity, but high permeability is mainly contributed by microcracks (Figure 3(c)).

3.1.3. CPMI. For RIDP, the distribution of throat radius obtained by constant-rate mercury injection shows that the distribution of the throat in this kind of reservoir is more homogeneous. There are mainly the small-middle throats with a small number of large throats. The heterogeneity of the throat is medium, but the distribution is homogeneous with the large average throat radius. (Table S1, Figure 4(a)).

For RDIP, the distribution of throat radius obtained by constant-rate mercury injection shows that the distribution of the throat is simpler with regard to this kind of reservoir mainly consisting of small throats and relatively rare throats with a radius longer than $1 \mu \mathrm{m}$ (Table S1, Figure 4(b)).

For RMMP, the throats of less than $0.1 \mu \mathrm{m}$ and more than $10 \mu \mathrm{m}$ all developed to a certain degree. Generally speaking, these reservoirs are dominated by micropores, but the development of microcracks made certain macroporous laryngeal development with the characteristics of dual plateaus in pore body curve (Table S1, Figure 4(c)). Although there are distinct differences among the three types of reservoirs in throat parts, the pore curves are relatively unformed, indicating that throats are predominant governing factors on pore networks, when compared with the pores.

3.1.4. NMR. For RIDP, the state of nuclear magnetic resonance $T_{2}$ spectrum is bimodal which is high in right and low in left. The irreducible water saturation of these samples is relatively low, the movable fluid saturation is relatively high, and the movable fluid mainly occurs in the mesopores and a small number of macropores. Taking $<10 \mathrm{~ms}$, $10 \sim 100 \mathrm{~ms}$, and $>100 \mathrm{~ms}$ as the threshold of clay mineral micropores, mesopores, and macropores [31-33], the major pore type of this reservoir is macropores and mesopores; the proportion of micropores are low (Figure 5).

For RDIP, the magnetic resonance $T_{2}$ spectrum is unimodal. This kind of reservoir is mainly composed by microsmall pore, the irreducible water saturation of these samples is relatively high, and the movable fluid saturation is relatively low. Taking $<10 \mathrm{~ms}, 10 \sim 100 \mathrm{~ms}$, and $>100 \mathrm{~ms}$ as the threshold of clay mineral micropores, mesopores, and macropores, the major pore type of this reservoir are micropores and mesopores; the proportion of macropores is low (Figure 5).

For RMMP, the magnetic resonance $T_{2}$ spectrum is bimodal. The microcracks increase permeability through fluid penetration. However, the increase of porosity cementation and throats make the lowest movable fluid saturation in 


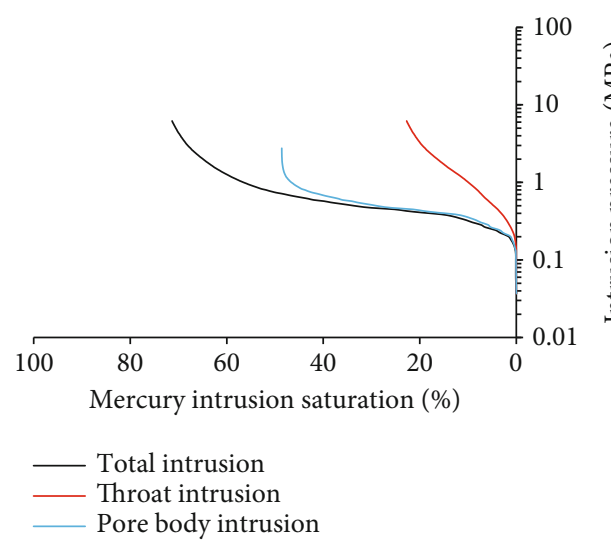

(a)

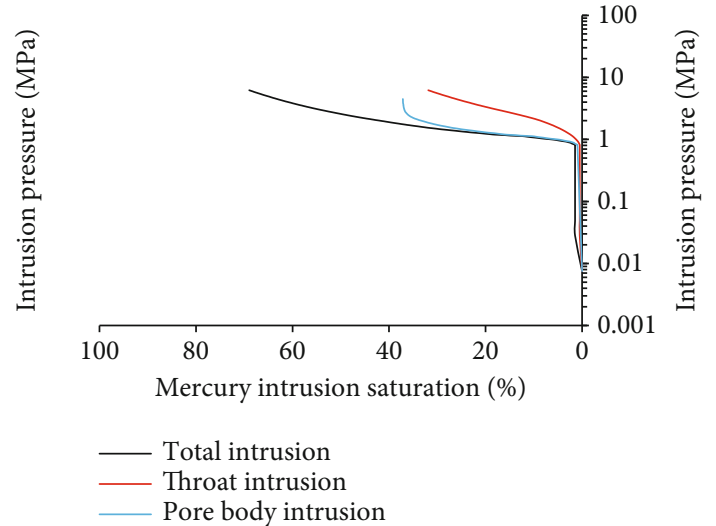

(b)

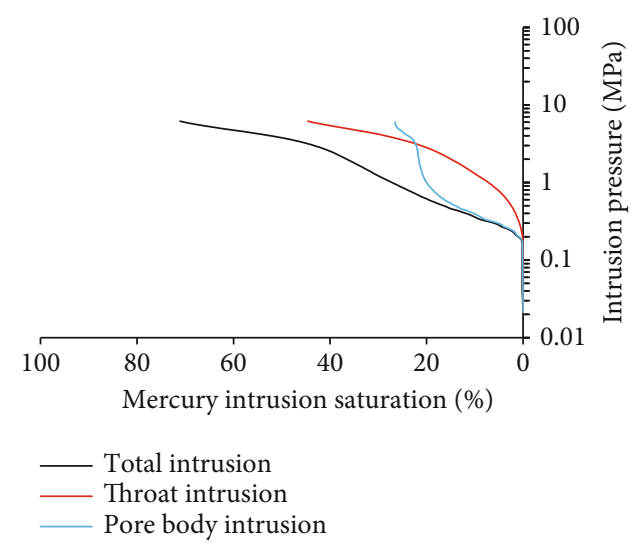

(c)

FIGURE 4: Constant rate mercury injection curves of the three typical samples.

this kind of reservoir. The peak amplitude and slow decline at $100 \mathrm{~ms}$ can be used as the identification mark of such microcracks (Figure 5).

\subsection{Effect of Reservoir Pore and Throat Parameters on} Movable Fluid Parameters. Table S1 and Figure 6 show the correlations of movable fluid percentage, average throat radius, mainstream throat radius, sorting coefficient, and pore-throat ratio. It can be found that, apart from sample 5 which microcracks developed, the movable fluid percentage has good correlation with other parameters, the R-squared are greater than 0.5 , and the $\mathrm{R}$-squared of the mainstream radius is greater than that of the average radius. It demonstrates that the mainstream pore-throat radius is more closely related to the movable fluid percentage than the average ones, and the greater the difference between the mainstream and average radius is, the higher the movable fluid percentage is. These results show that the average throat radius has some limitations in characterizing the trend of movable fluid percentage, but the mainstream throat radius, which represents the seepage capacity [34], is more effective in reflecting the trend of movable fluid.

Apart from pore and throat size, the pore and throat heterogeneity also have a significant effect on movable fluid percentage, while their relationship depends on which experiment be chosen. Figure 6 shows that the pore-throat ratio from constant-rate mercury injection and the sorting coefficient from high-pressure mercury injection has a negative and positive relationship with movable fluid percentage, respectively. Due to the limited maximum injection pressures, the low limits of the porethroat radius of those experiments are different (the radius derived from HPMI were larger than that of CRMI) [35]. These demonstrate that the larger pores which corresponding to a high sorting coefficient have a great impact on high movable fluid percentage.

3.3. Effect of Reservoir Clay Minerals on Movable Fluid Parameters. The relationships between clay minerals and movable fluid percentage were vague, therefore, whether clay minerals promote, deteriorate, or had no impact on high movable fluid percentage need to be discussed (Figure 7). As Figures 7(a) and 7(b) have shown, high chlorite could both promote (sample 1 and 2) and deteriorate fluid flowability (sample 7 and 8), that is to say, few chlorites could prevent compaction while abundant chlorite would occlude the pore spaces (Figures $8(\mathrm{a})$ and $8(\mathrm{~b})$ ). The development of kaolinite was one of the indicators of feldspar dissolution, abundant dissolution pores corresponding to high porosity, and 


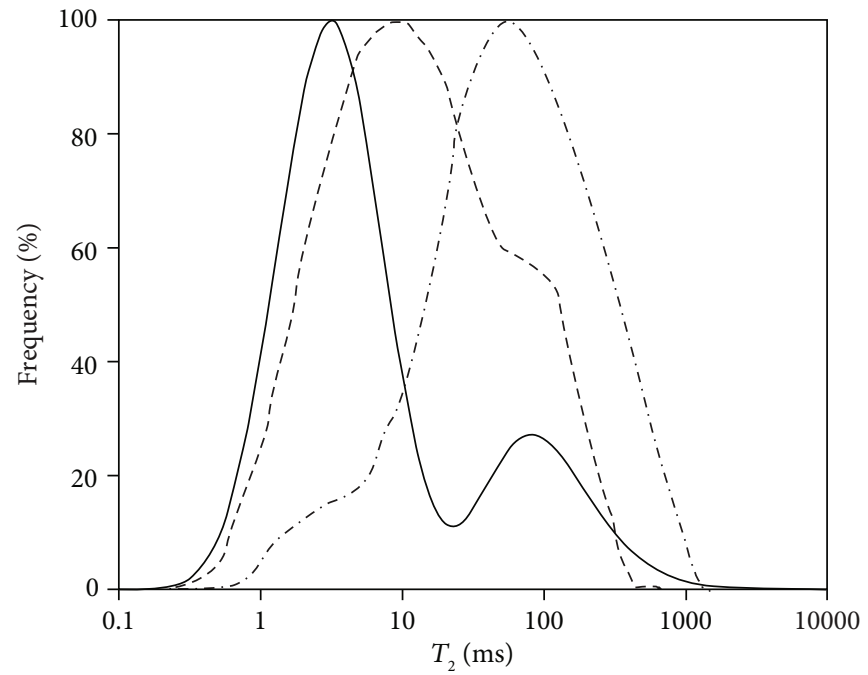

-.- Type 1

-- - Type 2

— Type 3

FIGURE 5: $T_{2}$ curves of the three typical samples.

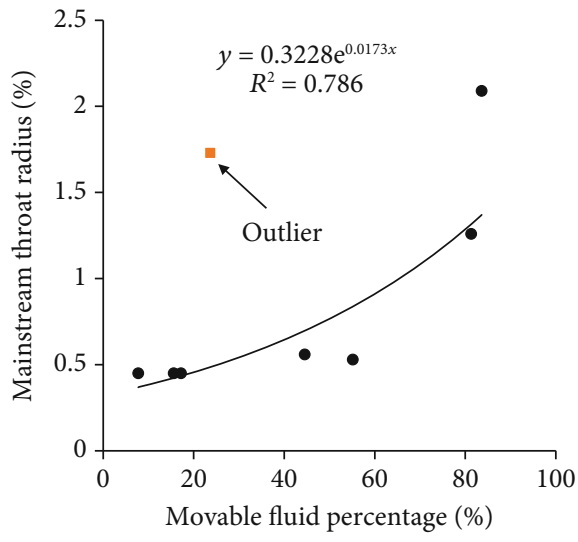

(a)

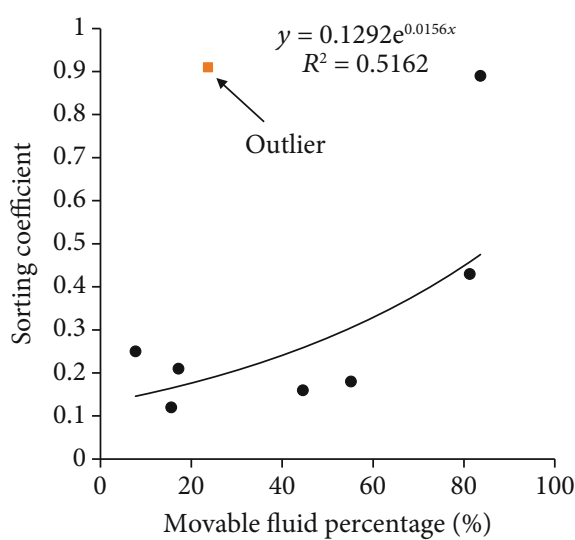

(c)

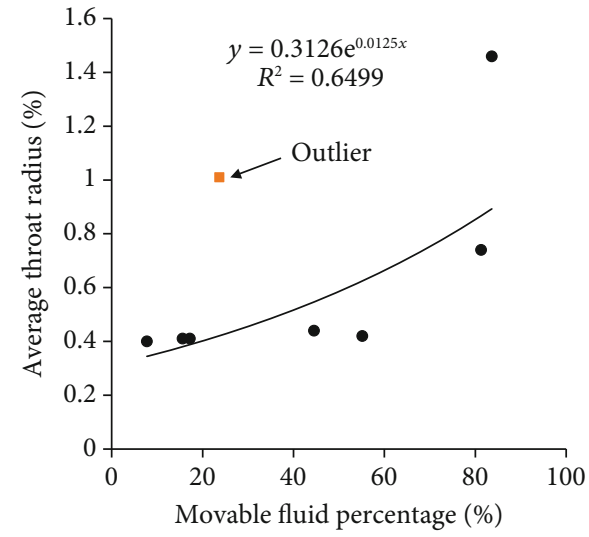

(b)

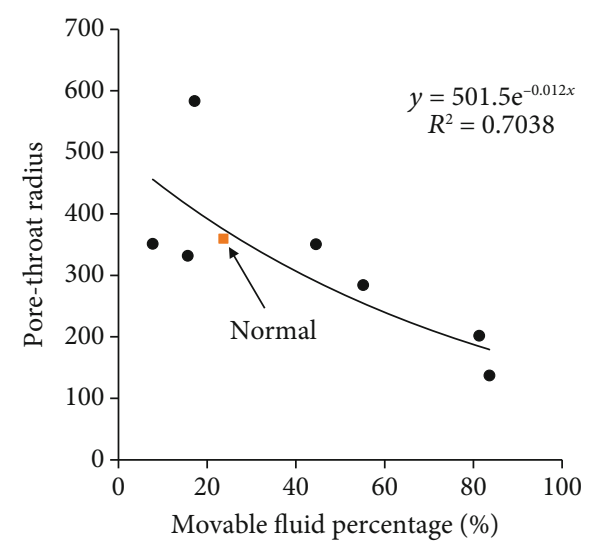

(d)

Figure 6: Correlations of movable fluid percentage and pore-throat related parameters. 


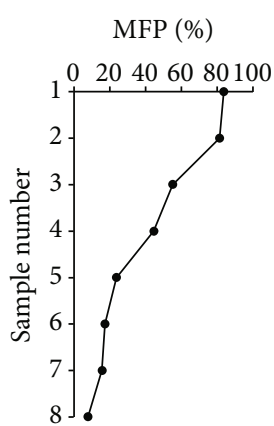

(a)

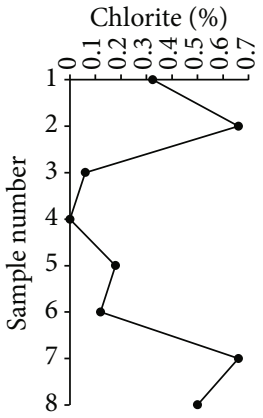

(b)

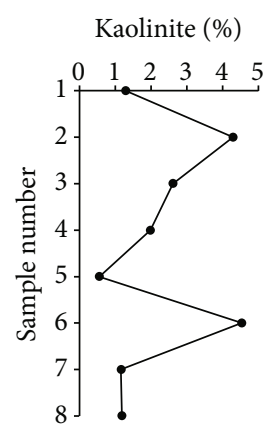

(c)

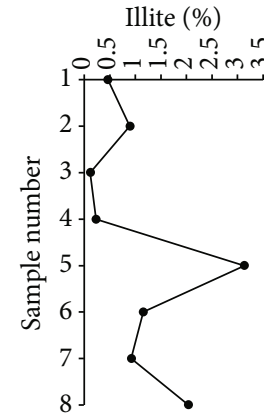

(d)

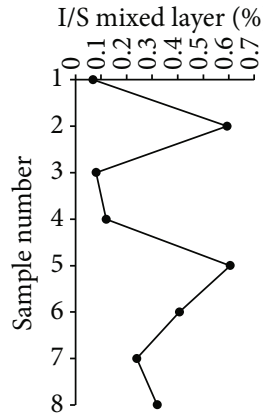

(e)

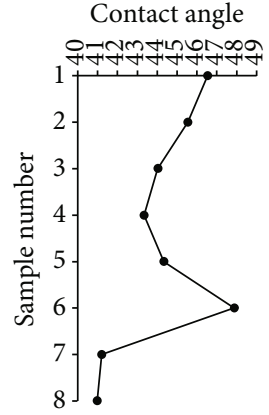

(f)

FIGURE 7: NMR, XRD, and wetting tests showing the variations of different samples.

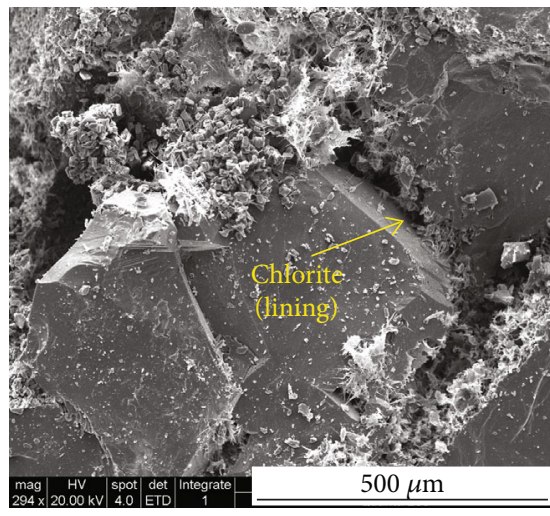

(a)

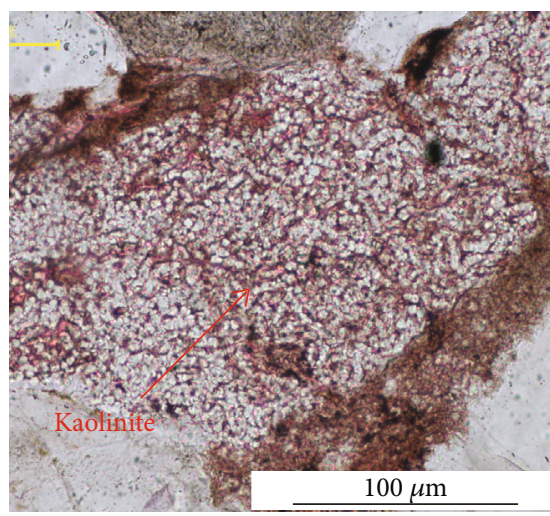

(c)

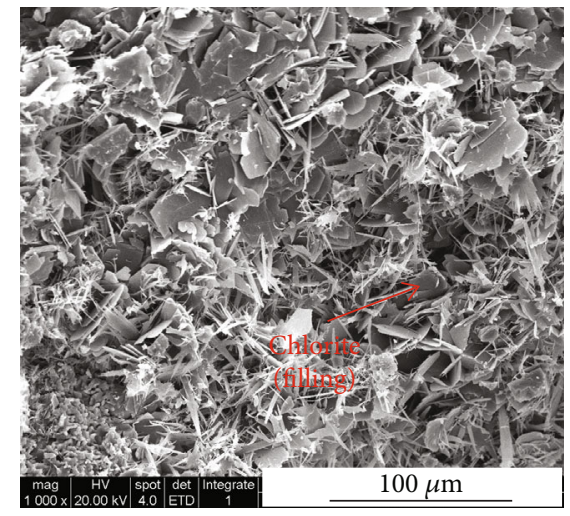

(b)

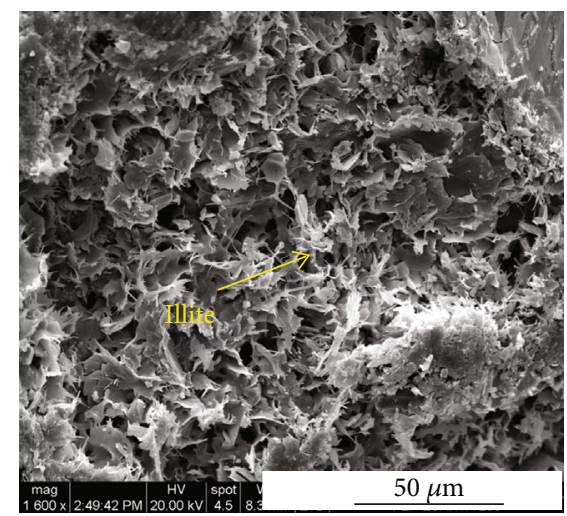

(d)

FIGURE 8: Representative thin section and SEM images to reveal the microscopic property.

therefore, represents high movable fluid percentage (Figure 8(c)). Illite and I/S mixed layer have distinct negative relationships with movable fluid percentage, suggesting that abundant illite and I/S mixed layer would deteriorate fluid flowability (Figure $8(\mathrm{~d})$ ).

3.4. Effect of Reservoir Wettability on Movable Fluid Parameters. Wettability has a great impact on NMR test [36-38]. As shown in Figure 7 and Table S2, the contact angle has a strong positive relationship with movable fluid percentage, indicating that hydrophile was generally corresponding to low fluid flowability. In order to detailing the reasons, four samples (3, 4, 7, and 8), which have similar pore-throat size, heterogeneity parameter, and permeability with similar movable fluid percentage were selected.

Figure 9 shows the spot variation of the droplet with different wettability. It illustrates that the displacement distance of the droplet with the same force varies a lot, suggesting that the interfacial tension has great impact on the fluid flowability. With the decrease of contact angle (increase of interfacial tension), the fluid movability increases, revealing that the wettability determines the movable fluid percentage by interfacial tension. 


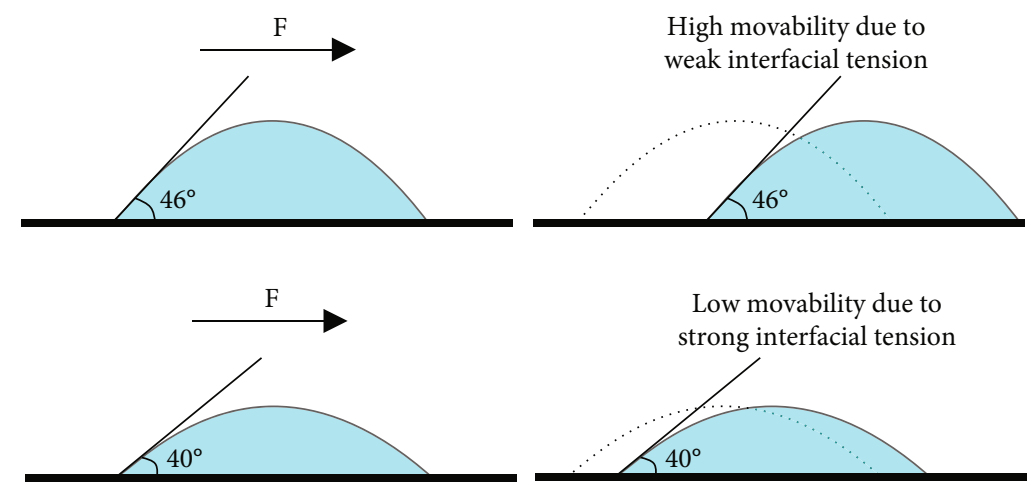

FIgURE 9: Schematic diagram of models for the droplet used to interpret the fluid movability.

\section{Conclusion}

(1) The reservoir could be divided into three types based on pore types, and the reservoirs with intergranulardissolved pore type are better than that of the dissolved-intergranular and pore plus microcrack pore type in terms of both the mobile fluid saturation and the pore-throat size

(2) Large throat and homogeneous pore-throat network would promote fluid flowability. Generally speaking, the higher the proportion of macropores are, the greater the saturation of the movable fluid is. The increase of hydrophilic clay mineral makes the water film thickness increases, which leads to the small throat stuffed and the mobile fluid percentage reduced

(3) Wettability has a significant impact on movable fluid; high flowability is resulted from weak wettability due to the reduction of interfacial tension.

\section{Data Availability}

The experimental data used to support the findings of this study are included in the manuscript.

\section{Conflicts of Interest}

The authors declare no conflict of interest.

\section{Acknowledgments}

This research was financially supported by Open Fund of Key Laboratory of Coal Resources Exploration and Comprehensive Utilization, Ministry of Land and Resources (KF2019-1, KF2020-2, KF2021-7); Engineering Research Center of Development and Management for Low to Ultra-Low Permeability Oil \& Gas Reservoirs in West China (Ministry of Education) Xi'an Shiyou University, grant number KFJJ-XB-2019-2; Young science and Technology Talents Foundation of Shaanxi province, grant number 2019KJXX-054; National Natural Science Foundation of China, grant numbers (41702146, 51934005); Open Fund of Shaanxi Key Laboratory of Advanced Stimulation Technology for Oil \& Gas Reservoirs, grant number 20JS120.

\section{Supplementary Materials}

Table S1: statistics of macro- and microparameters in the research area. $((+)$ means positive correlation, $(-)$ means negative correlation, A represent reservoirs with the intergranular-dissolved pore type, $\mathrm{B}$ represent reservoirs with the dissolved-intercrystalline pore type, $C$ represent reservoirs with pore plus micro-cracks). Table S2: statistics of clay content and wettability index in the research area. (Supplementary Materials)

\section{References}

[1] J. Dai, Y. Ni, and X. Wu, "Tight gas in China and its significance in exploration and exploitation," Petroleum Exploration and Development, vol. 39, no. 3, pp. 277-284, 2012.

[2] T. Wang and B. Lin, "Impacts of unconventional gas development on China's natural gas production and import," Renewable and Sustainable Energy Reviews, vol. 39, pp. 546-554, 2014.

[3] Z. Rui, K. Cui, X. Wang et al., "A quantitative framework for evaluating unconventional well development," Journal of Petroleum Science and Engineering, vol. 166, pp. 900-905, 2018.

[4] H. Y. Pan, D. W. Yin, N. Jiang, and Z. G. Xia, "Crack initiation behaviors of granite specimens containing crossing-doubleflaws with different lengths under uniaxial loading," Advances in Civil Engineering, vol. 2020, Article ID 8871335, 13 pages, 2020.

[5] X. Wang, C. Liu, S. Chen, L. Chen, K. Li, and N. Liu, "Impact of coal sector's de-capacity policy on coal price," Applied Energy, vol. 265, p. 114802, 2020.

[6] H. Gao and H. Li, "Pore structure characterization, permeability evaluation and enhanced gas recovery techniques of tight gas sandstones," Journal of Natural Gas Science and Engineering, vol. 28, pp. 536-547, 2016.

[7] M. Schmitt, C. P. Fernandes, F. G. Wolf, J. A. Bellini da Cunha Neto, C. P. Rahner, and V. S. Santiago dos Santos, "Characterization of Brazilian tight gas sandstones relating permeability and Angstrom-to micron-scale pore structures," Journal of Natural Gas Science and Engineering, vol. 27, pp. 785-807, 2015.

[8] J. Wang, Y. Zhang, Z. Qin, S. G. Song, and P. Lin, “Analysis method of water inrush for tunnels with damaged waterresisting rock mass based on finite element method-smooth 
particle hydrodynamics coupling," Computers and Geotechnics, vol. 126, p. 103725, 2020.

[9] J. T. Chen, J. H. Zhao, S. C. Zhang, Y. Zhang, F. Yang, and M. Li, "An experimental and analytical research on the evolution of mining cracks in deep floor rock mass," Pure and Applied Geophysics, vol. 177, no. 11, pp. 5325-5348, 2020.

[10] A. Legchenko, J. M. Baltassat, A. Beauce, and J. Bernard, "Nuclear magnetic resonance as a geophysical tool for hydrogeologists," Journal of Applied Geophysics, vol. 50, no. 1-2, pp. 21-46, 2002.

[11] B. Cowan, "Nuclear magnetic resonance and relaxation," Journal of Chemical Physics, vol. 45, no. 5, pp. 185-187, 2010.

[12] A. Dillinger and L. Esteban, "Experimental evaluation of reservoir quality in Mesozoic formations of the Perth Basin (Western Australia) by using a laboratory low field nuclear magnetic resonance," Marine and Petroleum Geology, vol. 57, pp. 455$469,2014$.

[13] C. X. Wang, B. T. Shen, J. T. Chen et al., "Compression characteristics of filling gangue and simulation of mining with gangue backfilling: an experimental investigation," Geomechanics and Engineering, vol. 20, no. 6, pp. 485-495, 2020.

[14] N. Jiang, C. X. Wang, H. Y. Pan, D. Yin, and J. Ma, “Modeling study on the influence of the strip filling mining sequence on mining-induced failure," Energy Science \& Engineering, vol. 8, no. 6, pp. 2239-2255, 2020.

[15] D. Ren, D. Zhou, D. Liu, F. Dong, S. Ma, and H. HuangFormation mechanism of the Upper Triassic Yanchang Formation tight sandstone reservoir in Ordos BasinTake Chang 6 reservoir in Jiyuan oil field as an example," Journal of Petroleum Science and Engineering, vol. 178, pp. 497-505, 2019.

[16] H. Ming, W. Sun, L. Zhang, and Q. Wang, "Impact of pore structure on physical property and occurrence characteristics of moving fluid of tight sandstone reservoir, taking He 8 reservoir in the east and southeast of Sulige Gasfield as an example," Journal of Central South University: Science and Technology, vol. 46, no. 12, pp. 4556-4567, 2015.

[17] G. Feng, Y. Kang, X. C. Wang, Y. Hu, and X. Li, "Investigation on the failure characteristics and fracture classification of shale under Brazilian test conditions," Rock Mechanics and Rock Engineering, vol. 53, no. 7, pp. 3325-3340, 2020.

[18] G. Feng, X. C. Wang, M. Wang, and Y. Kang, "Experimental investigation of thermal cycling effect on fracture characteristics of granite in a geothermal-energy reservoir," Engineering Fracture Mechanics, vol. 235, article 107180, 2020.

[19] H. Huang, T. Babadagli, X. Chen, H. Li, and Y. Zhang, "Performance comparison of novel chemical agents for mitigating water-blocking problem in tight gas sandstones," SPE Reservoir Evaluation \& Engineering, vol. 23, no. 4, pp. 1150-1158, 2020.

[20] J. Xu, A. Haque, W. Gong et al., "Experimental study on the bearing mechanisms of rock-socketed piles in soft rock based on micro X-ray CT analysis," Rock Mechanics and Rock Engineering, vol. 53, no. 8, pp. 3395-3416, 2020.

[21] D. Xiao, S. Jiang, D. Thul, S. Lu, L. Zhang, and B. Li, "Impacts of clay on pore structure, storage and percolation of tight sandstones from the Songliao Basin, China: implications for genetic classification of tight sandstone reservoirs," Fuel, vol. 211, pp. 390-404, 2018.

[22] C. Zhu, M. C. He, M. Karakus, X. B. Cui, and Z. G. Tao, "Investigating toppling failure mechanism of anti-dip layered slope due to excavation by physical modelling," Rock Mechanics and Rock Engineering, vol. 53, no. 11, pp. 5029-5050, 2020.

[23] F. Wu, J. Zhao, S. Yan et al., "Geological characteristics and exploration prospect of Upper Paleozoic reservoirs in Yanchang area, Ordos Basin," Petroleum Exploration and Development, vol. 34, no. 4, pp. 401-405, 2007.

[24] Q. Yin, H. Jing, G. Ma, H. Su, and R. Liu, "Investigating the roles of included angle and loading condition on the critical hydraulic gradient of real rock fracture networks," Rock Mechanics and Rock Engineering, vol. 51, no. 10, pp. 31673177, 2018.

[25] W. Zhao, C. Bian, and Z. Xu, "Similarities and differences between natural gas accumulations in Sulige Gasfield in Ordos Basin and Xujiahe Gasfield in Central Sichuan Basin," Petroleum Exploration and Development, vol. 40, no. 4, pp. 400408, 2013.

[26] H. Y. Wang, A. V. Dyskin, E. Pasternak, P. Dight, and M. Sarmadivaleh, "Experimental and numerical study into 3D crack growth from a spherical pore in biaxial compression," Rock Mechanics and Rock Engineering, vol. 53, no. 1, pp. 77102,2020

[27] H. Wang, A. Dyskin, and E. Pasternak, "Comparative analysis of mechanisms of 3-D brittle crack growth in compression," Engineering Fracture Mechanics, vol. 220, p. 106656, 2019.

[28] H. Yang, J. Fu, X. Wei, and X. Liu, "Sulige field in the Ordos Basin: geological setting, field discovery and tight gas reservoirs," Marine and Petroleum Geology, vol. 25, no. 4-5, pp. 387-400, 2008.

[29] SY/T 5346-2005, "Petroleum and natural gas industry standard. Rock capillary pressure measurement," National Development and Reform Commission of China, 2005, in Chinese.

[30] SY/T 5336-2006, "Petroleum and natural gas industry standard. Practices forcore analysis," National Development and Reform Commission of China, 2006, in Chinese.

[31] W. Liu, Z. Xiao, and S. Yang, "Comparative studies on methods of evaluation of reservoir pore structure by using NMR (nuclear magnetic resonance) well logging data," Oil Geophysical Prospecting, vol. 44, no. 6, pp. 773-778, 2009.

[32] H. Li, H. Guo, and Q. Liu, "NMR experimental study of water displacing oil of tight oil reservoir," Journal of Central South University: Science and Technology, vol. 45, no. 12, pp. 43704376, 2014.

[33] D. Xiao, S. Lu, Z. Lu, W. Huang, and M. Gu, "Combining nuclear magnetic resonance and rate-controlled porosimetry to probe the pore-throat structure of tight sandstones," Petroleum Exploration and Development, vol. 43, no. 6, pp. 1049-1059, 2016.

[34] L. Ye, B. Zhong, and W. Xiong, "An integrated evaluation method of Xujiahe low-permeability sandstone gas reservoirs in middle Sichuan Basin," Natural Gas Industry, vol. 32, no. 11, pp. 43-46, 2012, in Chinese.

[35] S. Yang and J. Wei, Reservoir Physics[M], Petroleum Industry Press, Beijing, 2004, in Chinese.

[36] W. Looyestijn, "Wettability index determination from NMR logs," Petrophysics, vol. 49, no. 2, 2008.

[37] N. Zhang, W. Liu, Y. Zhang, P. Shan, and X. Shi, "Microscopic pore structure of surrounding rock for underground strategic petroleum reserve (SPR) caverns in bedded rock salt," Energies, vol. 13, no. 7, p. 1565, 2020.

[38] D. Liu, Z. Gu, R. Liang et al., "Impacts of pore-throat system on fractal characterization of tight sandstones," Geofluids, vol. 2020, Article ID 4941501, 17 pages, 2020. 